\title{
TECHNIQUE TO REPAIR IATROGENICALLY-DAMAGED ROOTS DURING POST CANAL PREPARATION USING RESIN COMPOSITE AND OPTIC FIBRE POSTS
}

J.L. Lui. Technique to repair iatrogenically-damaged roots during post canal preparation using resin composite and optic fibre posts. Annal Dent Univ Malaya 2007; 14: 14-18.

\begin{abstract}
During post crown restoration, the preparation of the post canal can be fraught with difficulties resulting in widening, gouging and transportation of the post canal; sometimes with near root perforation. A technique is described to repair such iatrogenically damaged internal root canal walls using reinforcing resin composite and optic glass fibre posts. The root dentine, resin composite and glass fibres, having similar moduli of elasticity, will result in a repaired root with a 'monolithic' structure and possessing numerous desirable characteristics. This repair technique can easily be carried out in one sitting at the chairside thereby allowing the continued serviceability of the iatrogenically compromised root-filled tooth.
\end{abstract}

Key words: post crown; repair; iatrogenically damage root; reinforcement; resin composite; optic glass fibre post; aesthetics

\section{INTRODUCTION}

The construction of a post crown to restore an endodontically treated tooth is a challenging procedure. This is because of the need to remove root filling material from a narrow restricted root canal and the preparation of a post canal space to receive a suitable post. The procedure becomes more complicated if the access to instrumentation is less than ideal and for the less experienced the drilling, when also carried out blind, is not only daunting but can consequently result in poor canal preparation and damage to the root.

A technique had been introduced to reconstitute lost dentine structure by intraradicular composite reline of overflared canal space(1) and root reinforcement in widening of the canal space during endodontic therapy to retrieve a broken instrument(2). Resin composite is a suitable reinforcing and core build-up material in clinical practice. The use of chemical-curing composite inside a root canal space can be fraught with difficulties as there is no control once the rapidly polymerizing composite is placed deep inside the
Original Article

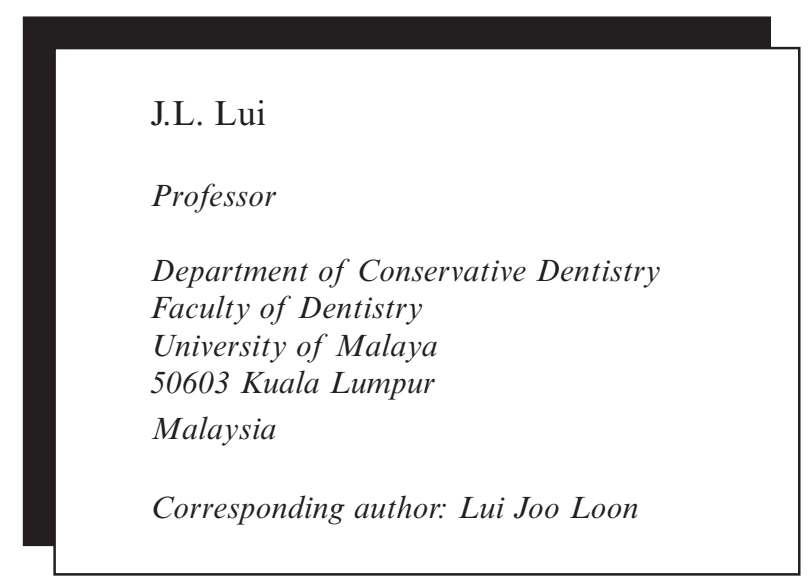

root canal. Light-curing composite gives better control but, unfortunately, the depth of cure is limited to $2-4 \mathrm{~mm}$. The use of light-transmitting plastic posts has solved the problem of limited depth of cure inside the canal space $(2,3)$. Following removal of the light-transmitting plastic post, a prefabricated or customized post will subsequently have to be placed thus necessitating an additional procedure.

The optic glass fibre post not only transmits light to polymerize the reinforcing resin composite inside the root canal space but, unlike the lighttransmitting plastic post, it becomes at the same time, bonded into the root to allow immediate composite core build-up. Such a 'monolithic' structure, with the bonded resin composite and glass fibre post having a modulus of elasticity close to dentine $(4,5)$, has the ability to reduce the incidence of catastrophic root fracture (6) compared to the usual post crown where stresses are highly concentrated at the coronal third of the root (7). The use of non-metallic glass fibre post with a suitable shade of tooth-coloured composite will achieve an overall aesthetically pleasing result (8) especially when a final ceramic crown is placed.

\section{TECHNIQUE}

In this technique to repair iatrogenically-damaged, non-perforated roots during post canal preparation, repair was demonstrated to be carried out at the apical portion (Figure 1a \& b), mid level (Figure 2a $\&$ b) and entire side (Figure $3 \mathrm{a}, \mathrm{b} \& \mathrm{c}$ ) of three post canal spaces. The optic glass fibre posts used were the Luscent Anchors (Dentatus AB, Hagersten, Sweden) and the reinforcing resin composite was the light-curing hybrid Spectrum TPH (Dentsply DeTrey 
Gmbh, D-78467 Konstanz, Germany)(9). The treatment procedure is as follows:

1. Take a radiograph to assess the direction, position and extent of damage.

2. If the post canal had been misdirected, the correct root canal direction following the root filling must be re-established, including modifying the access cavity.

3. Refine the post canal walls with a suitable size marked reamer (Dentatus AB) from the Luscent Anchors set to fit a matching fibre post unless the post canal had been grossly enlarged.

4. Acid-etch the internal walls of the canal and root face using conditioner gel (Dentsply DeTrey Gmbh), rinse and remove excess moisture with paper points.

5. Apply bonding agent and/or adhesive (Prime \& Bond NT, Dentsply DeTrey Gmbh) to the etched surfaces.

6. Dispense from the compule a selected shade of Spectrum TPH into the bonded canal.

7. Adapt the dispensed composite using suitable composite instruments and remove any excess. Then, insert a corresponding/matching size Luscent Anchor to its predetermined length as indicated by a depth marker. In iatrogenically misdirected post canal, two fibre posts; one into the misdirected and the other into the actual canal, may be required (Figure 1b).

8. Place the light probe of the curing unit over the fibre post to transmit light for one minute into the canal to polymerize the surrounding composite.

9. Remove the depth marker ring and shorten the now bonded fibre post to a suitable height using water-cooled diamond bur. Pre-shortening of the fibre post using a suitable disc may be first carried out prior to its insertion into the composite-filled canal.

10. Build up the core using the Spectrum TPH composite and then refine the preparation to support a crown.

\section{DISCUSSION}

The preparation of root canals for restoration of endodontically treated teeth with post crowns can result in disastrous consequences if the post canal preparation had not been carried judiciously. The worst case scenario would have been root perforation. Weakening, damage and near perforation of root canal walls could jeopardize the continued restoration with post crowns. Figures 13 demonstrated the kind of damage from post crown

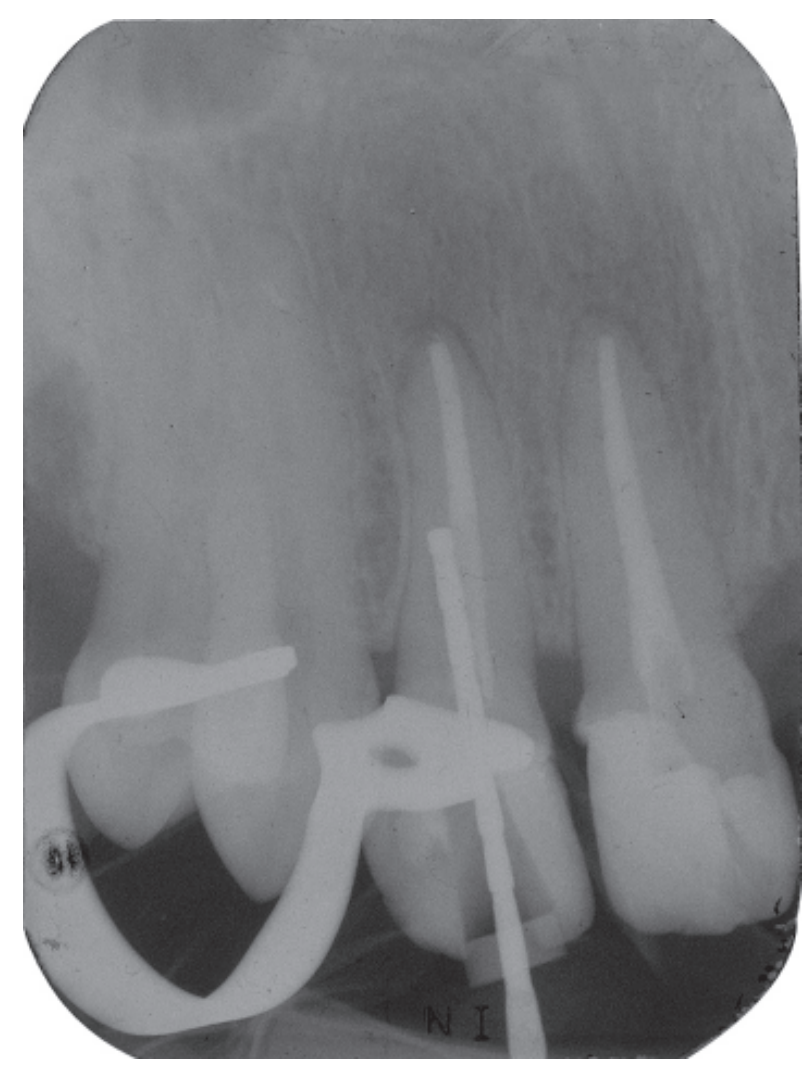

Figure 1a: Check radiograph showing prefabricated post misdirected distally at the apical end of the prepared post canal of 12. Note the presence of residual root filling at the mesial wall.

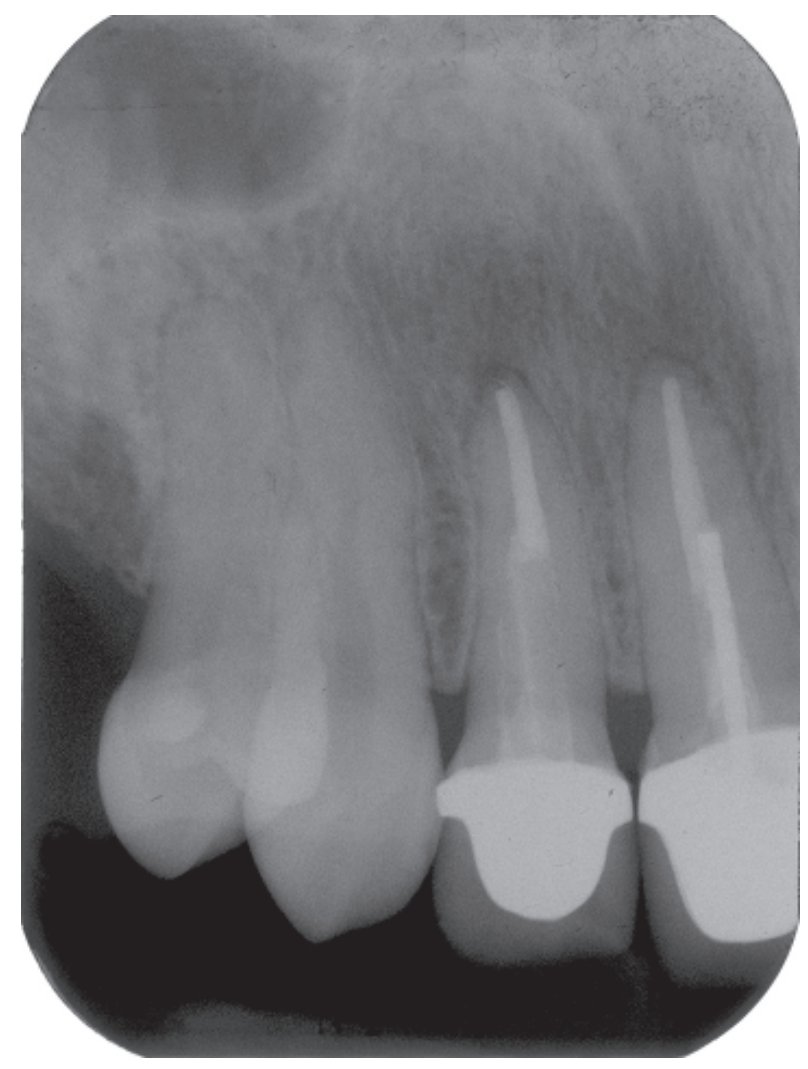

Figure 1b: Radiograph showing two glass fibre posts (appearing translucent in x'rays) and reinforcing resin composite (radiopaque) in the repair of the damaged canal following cementation of the crown. 


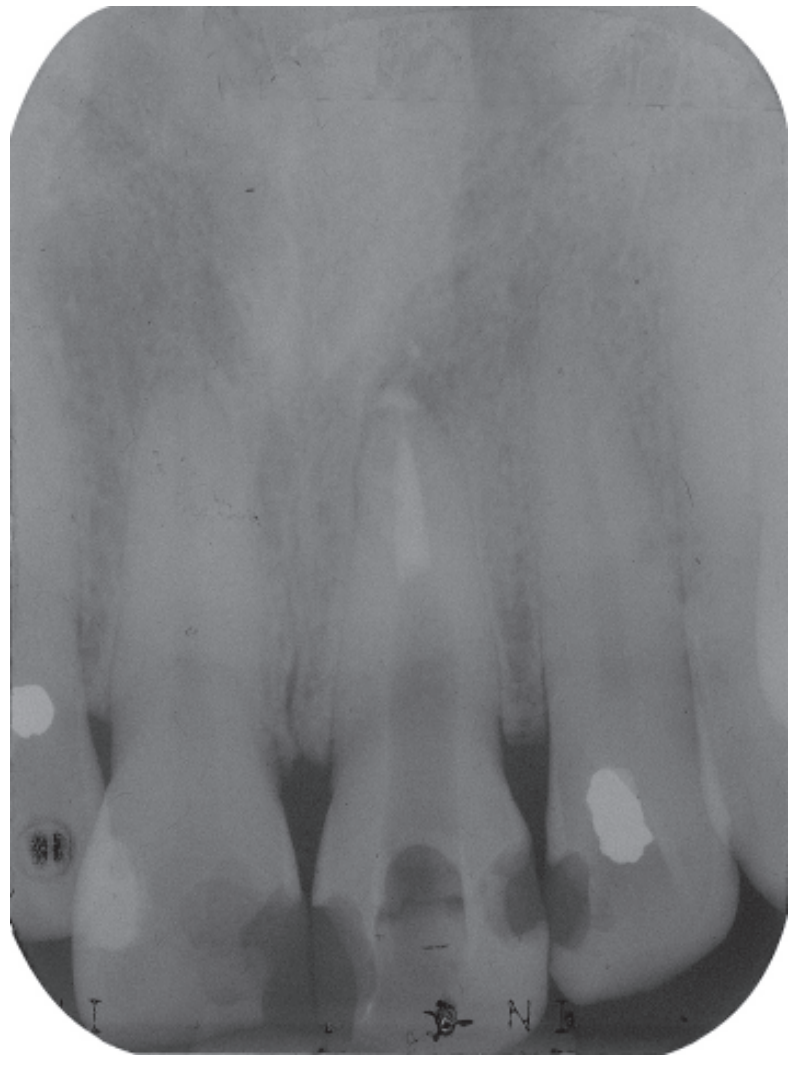

Figure 2a: Iatrogenic widening at about the mid level towards the distal wall of the prepared post canal in 21 .

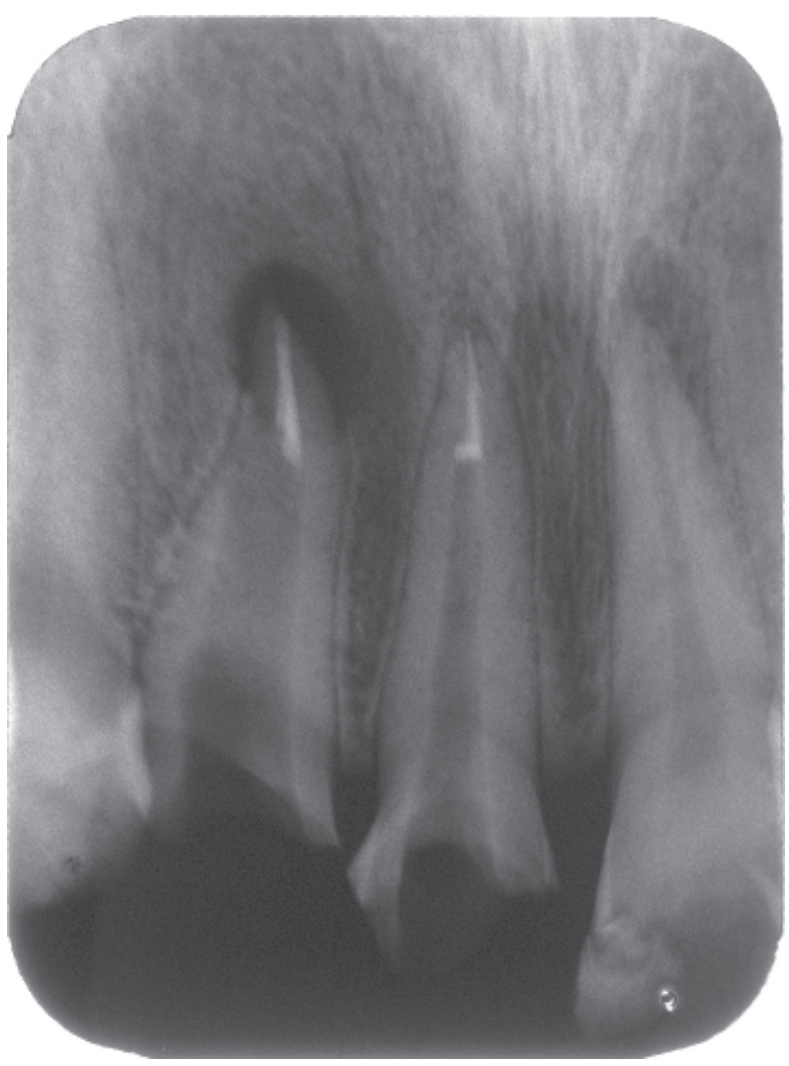

Figure 3a: Gross over-preparation with near perforation at the distal wall of 12 .

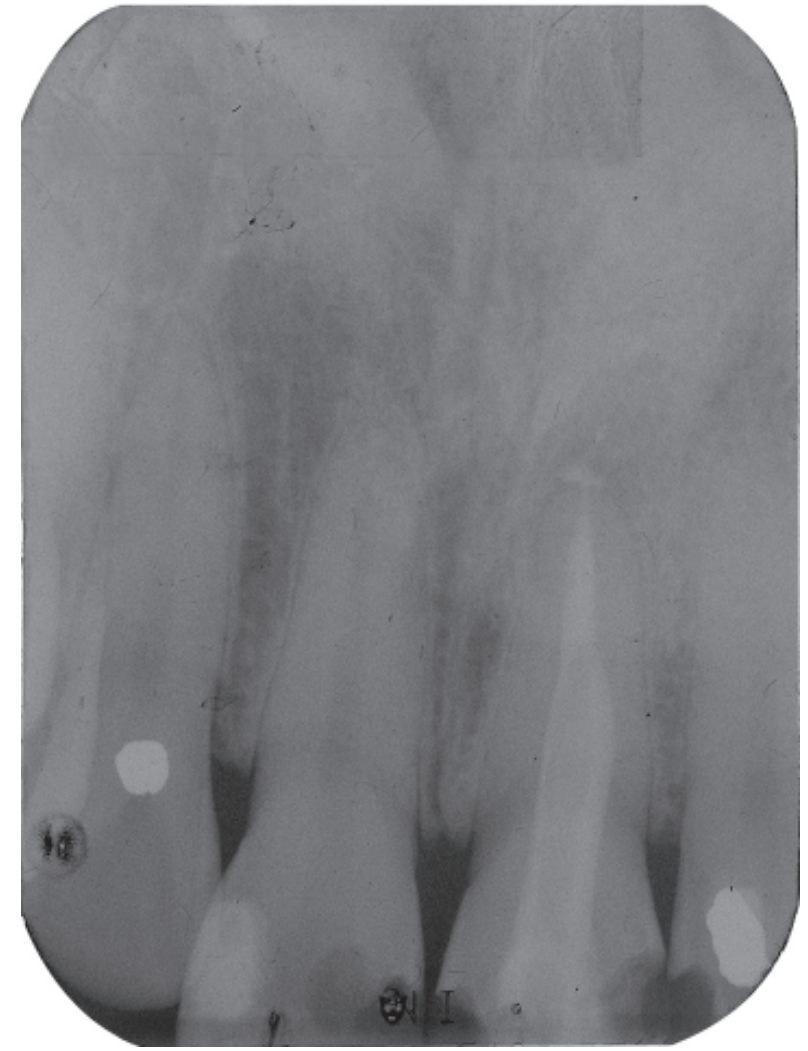

Figure 2b: Repair of the widened post canal using a reline of resin composite and bonded optic glass fibre post.

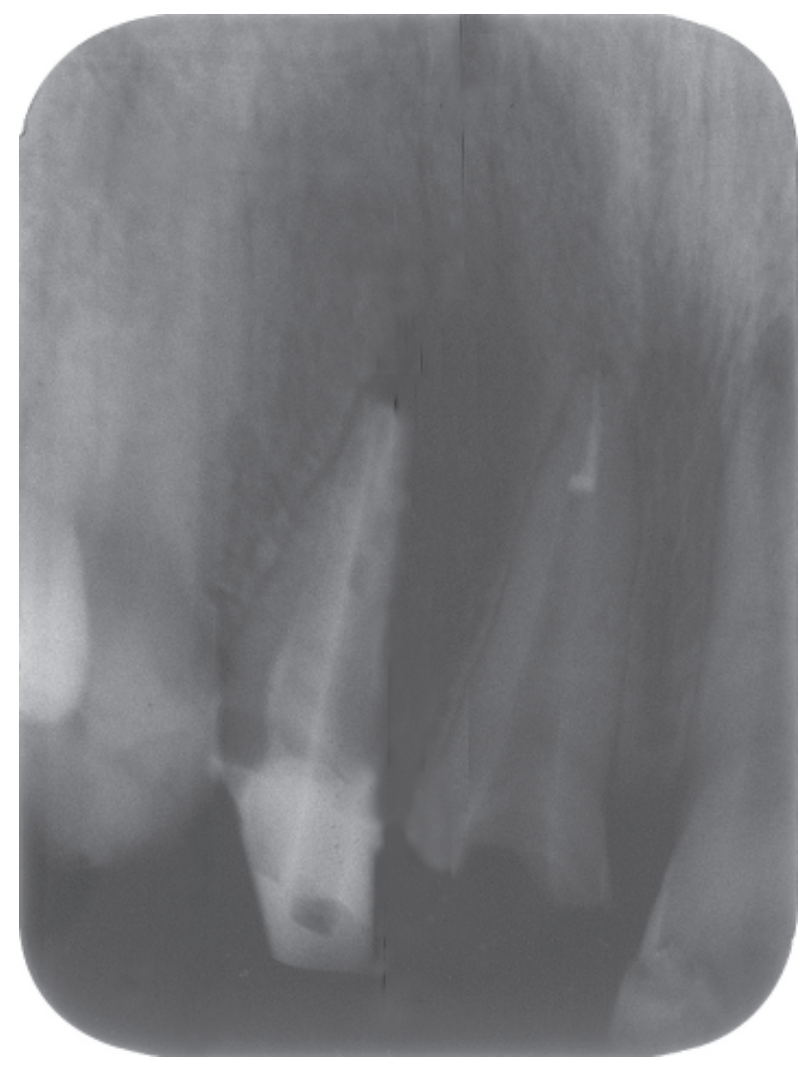

Figure 3b: Repair completed and composite core built up. 


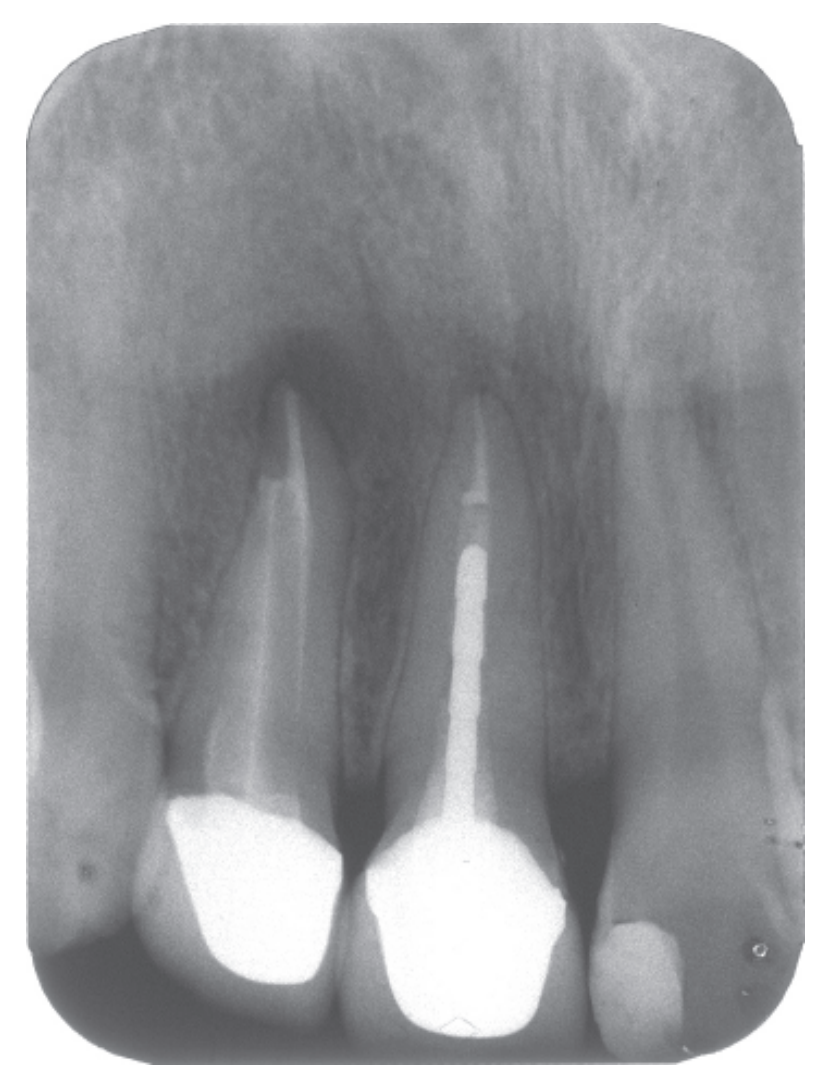

Figure 3c: The badly-damaged 12 now supporting a metal-ceramic crown.

preparation by a few undergraduate dental students of the Faculty of Dentistry, University of Malaya. The lack of clinical experience and understanding of the direction of root canals coupled with the use of rotary instrumentation in a poorly negotiated working space can therefore compromise the integrity of internal root structure ending for some in damage and near perforations.

The resin composite has been accepted as a strong reinforcing material for weakened teeth once it has been properly bonded to tooth substances. The use of light-transmission to polymerize resin composite placed deeply inside root canals had been widely used clinically to reinforce compromised roots arising from various causes (2, 10-14). Compromised roots reinforced in this manner were found to be $50 \%$ more resistant to fracture (15) and the retentive value of the composite reinforcement bonded to the canal walls was found to be significantly higher than that of cast posts cemented using zinc phosphate (16).

Using optic glass fibre light-transmitting posts in internally compromised endodontically treated roots not only ensure polymerization of the reinforcing resin composite to the damaged post canal walls but also bonding of the posts to the reinforcing repair composite. A 'monolithic' structure of similar moduli of elasticity comprising dentine, composite and glass fibres thereby result conferring numerous desirable characteristics to the restored tooth. Thus, there is no necessity to place any cast or prefabricated metal post as the bonded glass fibre post can provide retention for an aesthetically coloured composite core. This technique also has the advantage of reinforcement, post and core placement and construction in one sitting at the chairside without the need for laboratory fabrication. The very real problem of stress concentration $(6,7)$ attendant after metallic post and core treatment can thereby be eliminated. Also, post corrosion and masking of metallic cores will no longer be a problem.

\section{SUMMARY}

The repair and reinforcement of iatrogenicallydamaged roots during post canal preparation can be easily carried out with the use of resin composite and optic glass fibre posts. Following placement of a tooth-coloured core and aesthetic crown, the continued serviceability of a compromised tooth can be achieved.

\section{REFERENCES}

1. Lui JL. A technique to reinforce weakened roots with post canals. Endod Dent Traumatol 1987; 3: 310-4.

2. Lui JL. Composite resin reinforcement of flared canals using light-transmitting posts. Quintessence Int 1994; 25: 313-9.

3. Lui JL. Depth of composite polymerization within simulated root canals using lighttransmitting posts. Oper Dent 1994; 19: 165-8.

4. Torbjorner A, Karlsson S, Odman PA. Survival rate and failure characteristics for two post designs. J Prosthet Dent 1995; 73: 439-44.

5. Lassila LV, Tanner J, Le Bell AM, Narva K, Vallittu PK. Flexural properties of fiber reinforced root canal posts. Dent Mater 2004; 20: 29-36.

6. Akkayan B, Gulmez T. Resistance to fracture of endodontically treated teeth restored with different post systems. J Prosthet Dent 2002; 87: 431-7.

7. Assif D, Gorfil C. Biomechanical considerations in restoring endodontically treated teeth. J Prosthet Dent 1994; 71: 565-7.

8. Lui JL. Traumatisierte Schneidezahne im Wurzelwachstum stabilisieren und wiederherstellen. Aesthetische Zahnmedizin 2005; 8: 51-4. 
9. Lui JL. Aesthetic crowns bonded to fibreglass resin posts/cores in root-treated teeth. Asian $\mathrm{J}$ Aesthet Dent 2002; 10: 38-41.

10. Freedman G, Novak IM, Serota KS, Glassman GD. Intra-radicular rehabilitation: a clinical approach. Pract Periodont Aesthet Dent 1994; 6: 33-9.

11. Godder B, Zhukovsky L, Bivona PL, Epelboym D. Rehabilitation of thin-walled roots with light-activated composite resin: a case report. Compend Contin Educ Dent 1994; 15: 52-7.

12. Dickerson WG. The flexible trans-illuminating aesthetic post. Dent Today 1994; 13: 13-5.

13. Trushkowsky RD. Establishing an ideal post space in compromised teeth. Dent Econ 1995; 85: 68-9.
14. Lui JL. Reattachment of fractured root fragment and resin-composite reinforcement in a compromised endodontically-treated root: a case report. Dent Traumatol 2001; 17: 227-30.

15. Saupe WA, Gluskin AH, Radke RA Jr. A comprative study of fracture resistance between morphologic dowel and cores and a resinreinforced dowel system in the intraradicular restoration of structurally compromised roots. Quintessence Int 1996; 27: 483-91.

16. Tjan AHL, Tjan AH, Sun JC. Retention of Luminex post system. Oral Health 1997; 87: 315. 